\title{
Development of Conceptual Modular Building Unit Design Framework for Inexperienced Designers at the Pre-Design Stage
}

\author{
Jeonghoon Lee ${ }^{1}$,Moonseo Park ${ }^{2}$, Hyun-soo Lee ${ }^{3}$, Minjung Kim ${ }^{4}$, and Hosang Hyun ${ }^{5 *}$ \\ ${ }^{1}$ PhD Course Researcher, Department of Architecture, Seoul National University \\ ${ }^{2}$ Professor, Department of Architecture, Seoul National University \\ ${ }^{3}$ Professor, Department of Architecture, Seoul National University \\ ${ }^{4}$ M.S Course Researcher, Department of Architecture, Seoul National University \\ ${ }^{5}$ PhD Course Researcher, Department of Architecture, Seoul National University \\ ${ }^{5}$ Corresponding author's e-mail: hhs0518@snu.ac.kr
}

\begin{abstract}
Modular building construction has been increasing interest in adopting and utilizing off-site production technologies in house building in many countries and regions. Despite increasing interest of the modular building method, most of researchers were less interested in to support inexperienced designer who never experience in modular building design process. The objective of this paper is development of modular building construction design process framework, focusing on to provide for start-up modular company's inexperienced designers' improvement of modular building design understanding and reduce design errors at the enforcement design stage. To achieve this purpose, this paper adopts Building Systems Integration (BSI) concepts into framework and describes each step following proposed framework. This paper provides more easy to understand for inexperienced designer understanding the modular building design process than current textual guidelines. Subsequently, proposed framework can be translating for training materials to inexperienced modular building design process designers
\end{abstract}

\section{KEYWORDS}

Modular Building Construction, Modular Unit Design Process, Inexperienced Designer, Building Systems Integration ( BSI)

\section{INTRODUCTION}

Various researches have been performed flowing common modular construction process; design, factory production, transportation, and site installation. Most of researches were focusing on each steps specification problems of cost, time, and quality. Especially, lots of researchers were commonly emphasizing on importance of design process and quality of design [Yorkon Co., 2009; Alwisy, 2012; Manghadam, 2012; Mohammad, 2013]. Because designers are decide modular unit's detail of materials, performance, connection types, and on-site construction process at the pre-design stage. Also, designers need considering structural integrity, constructability, space efficiency, aesthetic and MEP connections. These efforts provide information on the maximum over the life of the building.

For these reasons, modular building designer's design quality improvement ways are constantly developing by various researchers in manufacture and building construction sectors. Most of common ways of technical approaches are using Building Information Modeling (BIM), $\mathrm{CAD} / \mathrm{CAM}$ and visualization programs. However, these ways are efficient in large and complex modular building construction projects to check the various types of materials relationship and 
need to experienced designers for using these programs. In modular building construction, of course, consist of various systems and multiple contractors are involved in each project for design quality improvement. Nevertheless, these systems are too expensive to adopt in characteristics of lower-story modular building construction and totally reliance on experienced designers make another unexpected costs need to company [HOIS, 2009; Senescu 2013]. Also, considering size of modular unit design company, especially start-up modular building company, these ways are hard to accept directly in modular design quality improvement ways and inexperienced modular unit designers are difficult to check the overall design process information flow. The objective of this paper is development of modular building construction design process framework, focusing on to provide for start-up modular company's inexperienced designers' improvement of modular building design understanding and reduce design errors in the pre-design stage.

\section{RESEARCH METHODS}

To achieve the objective, this paper adopts in the design process framework the concept of Building Systems Integration (BSI) method. This method is introduced in 1986 by American Institute of Association (AIA) published in building systems integration handbook. As described in table 1, it classified building systems into wall, ceiling, floor and open parts (Rush, 1986). These systems are composed mainly of structure, exterior finish, interior finish, and machinery distinct systems. More specifically, in AIA handbook explain a ball diagram advantages; “.....by using the matrix and the diagrams, the designer allows a symbol to represent the kind of integration desired among the systems without prejudging precisely the materials or systems involved and perhaps being hamstrung by the inherent configuration or geometry of those systems or materials.”. Although this approach developed long time ago, it is more appropriate for current modular building construction systems rather than used in conventional building construction systems. Because modular building units are composed mainly of various materials' assembly in factory, called manufacturing, so its connection types are more clearly defined at the pre-design stage rather than conventional building construction. Considering these characteristics of BSI and modular building unit design, at the pre-design stage, it is more helpful to designer check the various materials' interrelationship based on basic knowledge of design process.

All of the systems are described in five levels of integration; remote, connected, meshed, and unified. As described in Table 1 and Figure 1, these levels are based on physical relationship as represented by the "Ball diagram” (AIA, 1986).

Table 1. Four Distinct Systems in Building Systems Integration Method (Rush,1986)

\begin{tabular}{c|l|c}
\hline $\begin{array}{c}\text { Building } \\
\text { Systems }\end{array}$ & \multicolumn{1}{|c}{ Definition of Function } & Expression \\
\hline Structure & $\begin{array}{l}\text { The structure creates the equilibrium necessary to allow the } \\
\text { building to stand. It includes as frames, shells, slabs, bearing } \\
\text { walls. }\end{array}$ & $\begin{array}{l}\text { The function of the envelope is to protect the building from } \\
\text { penetration by the climate and physical degradation by } \\
\text { natural forces. The envelope is what is visible on the exterior } \\
\text { of the building }\end{array}$ \\
\hline
\end{tabular}




\begin{tabular}{c|l|c}
\hline Mechanical & $\begin{array}{l}\text { Mechanical systems provide services to the building and its } \\
\text { occupants. They control heat transfer, power supply, water } \\
\text { supply, and waste disposal. It also includes fire safety, } \\
\text { security system, control system, and conveyances. }\end{array}$ & $\mathrm{M}$ \\
\hline Interiors & $\begin{array}{l}\text { Interior systems are simply what are visible from inside a } \\
\text { habitable building. Exposed ducts and exposed waffle slabs } \\
\text { are included along with pure interior system. Each can be } \\
\text { treated separately in the sense that the interior systems of a } \\
\text { building can change after construction of the exterior, and } \\
\text { the exterior skin of the same building can be altered without } \\
\text { affecting the interior. }\end{array}$ & $\mathrm{I}$ \\
\hline
\end{tabular}

\begin{tabular}{|l|l|}
\hline Dhen two systems are remote from each other, they \\
\hline do not physically touch
\end{tabular}

Figure 1. Building Systems Integration Ball Diagram (Rush, 1986)

\section{DESIGN PROCESS IMPROVEMENT APPROACHES}

Most of researches are focused on automatically collect the design information ways and application to current design programs. Hu [2005] presents a model of geometric reasoning to automatic construction process planning of prefabricated buildings. This approach is considering each component's connection types for disassembly. Olson [2010] proposed hybridization of design for deconstruction and modularity concepts based on streamlining construction processes at various levels of pre-assembly; however, it did not propose how they chose design concepts and overall process. CHEN [2010] developed modular design logistics system and made design flow diagrams. This research focused on relationship of each module in logistics system. Park and Lee [2012] proposed a computer-aided design system (3D architecture) for modular houses. This research defined the materials functional specification of digital design system for modular building construction. Senescu et al [2013] develop the design process communication methodology (DPCM) based on organizational science, human computer interaction, and process modelling. This process aims to fill a gap between project information management and design process management fields. Building Information Modelling (BIM) represents one of the artificial intelligence tools explored as a modular unit design process improvement method. Especially, its usage can prove beneficial when multiple contractors participated in modular 
projects. Lu [2010] suggested process of implementation of BIM systems in modular construction process. Nawari O [2012] reviews the current state of BIM standards and its impact on off-site construction, after that proposed Information Delivery Manual (IDM) processes. This research contribution is defined the off-site construction data exchange functional requirements and extend an information exchange ways improved between architects, engineers, fabricators, and general contractors. Mogahadam et al. [2012] proposed BIM and modular construction manufacturing process (MCMPro) integrated models and performed simulations using Simpony.NET 3.5. After that, this research showed integrated process improvement through case study; however, suggested model is supposed all of the material information is already prepared in BIM database and it is useful at the detailed design phases by experienced designers

\section{BSI APPLICATION TO MODULAR UNITS PRE-DESING STEP}

This paper provide five steps of modular building design process framework; (1) identification of modular unit mass concept, (2) determine the materials and defined expression, (3) drawings BSI model structure, (4) combination of BSI structure based on pre-design concepts, (5) Finding an alternative. The proposed framework model is developed based on various international literature [Rush, 1986; Kagioglou, 2000; Yorkon Co, 2009; Smith, 2010; Knaack, 2012; Hassanain, 2013; Senescu, 2013] and BSI handbook.

\section{Activities in modular unit design process framework}

Step 1. Identification of Modular unit Mass Concept

In this step, modular unit designers decide a modular unit types and overall mass concept. For this work, designer needs four main information in this step; customer needs, environment characteristic, field geometric information, and general regulations. Customer needs consist of purpose of use (residential, hotel, hospital, and barracks), material performance levels, cost limitation, and space utilization. Especially, cost limitation is one of the most important variables in deciding a distribution of resource not only for modular building unit, also for conventional construction. In modular building construction, it uses in payment for direct cost and indirect cost; labor fee in factory and site, construction equipment, transportation, manufacturing and design fees. In this step, designer only considering the labor fee and unit price of material.

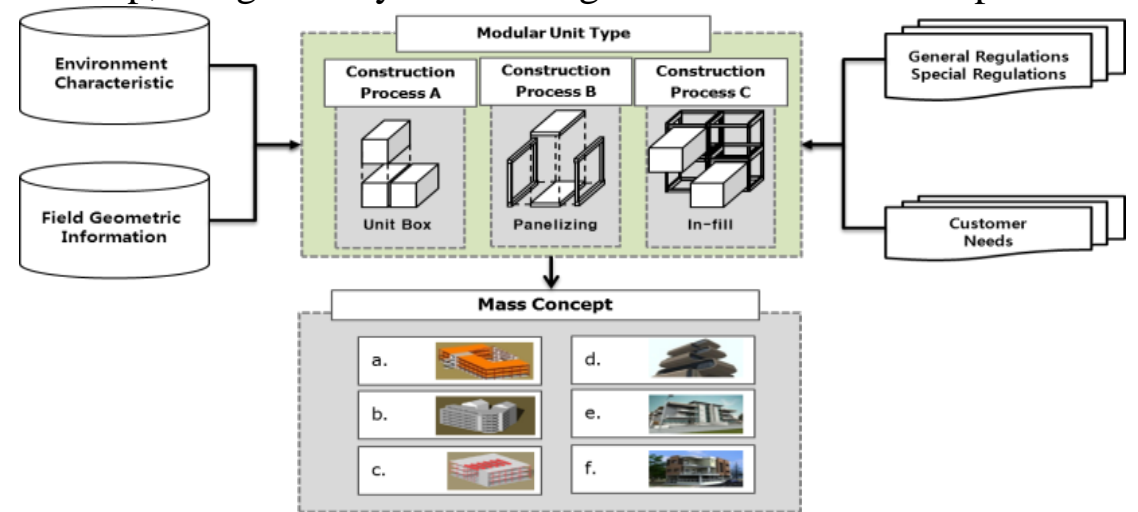

Figure 2 Step 1, identification of modular mass concept

Environment characteristic is can be said regional climate characteristic and field geometric information is more specific information of installation region physical conditions. These are possible to obtain from a meteorological office center or regional database. Based on the information, designer chooses the unit types; unit box, panelizing, and in-fill. It determined the 
modular building design mass concept and used to calculation for structure resistant from nature environment factors (Figure 2).

Step2. Determine the materials and defined expression

After the step 1, Figure 3 shows that designer performed each objective of modular design demands a set of factors to be considered. The main purpose of this design process framework development is provide to designer when the basic discussion with customer or other designer at the pre-design stage. Other factors considered when it fixing modular building systems, of course, but too much information concentrate in one place is can interfere with the designer's decision making at the pre-design stage. To determine the material physical life cycle, designer needs considering modularity as defined materials' combination in modular unit. This consideration determines the designer's first decision making of material type and overall modular unit design concept. After choose the materials, defined the material's expression name for ball diagrams. When it defined, designer has to arrange all of materials as ball diagram definition in BSI. If modular unit main structure consist four H-beams, each beam has their own special symbol as S1, S-2, S-3, and S-4 following BSI expression

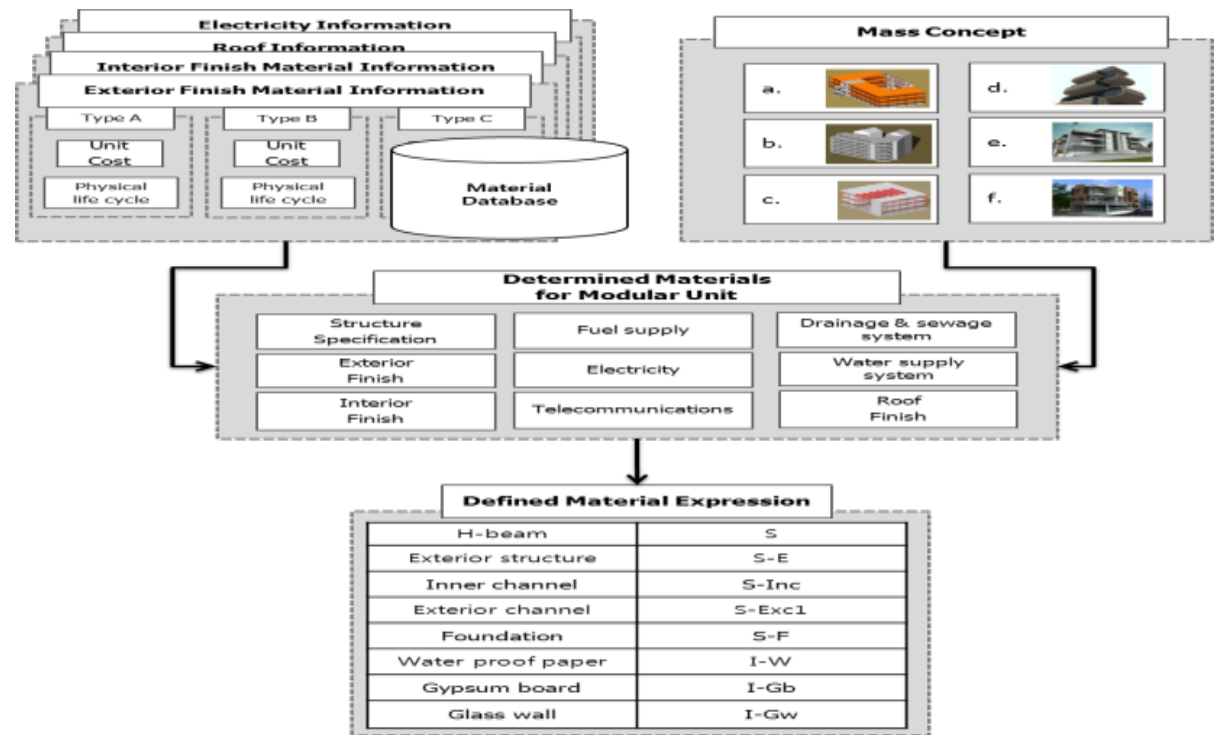

Figure 3 . Step 2, determine the materials and defined expression symbol

\section{Step3. Drawings BSI Model Structure}

Figure 4 show that designer creates the modular building's overall drawings by BSI method. Considering the process of BSI method, made by designer's manually, this classification makes confuse to inexperienced designer for overall concepts understanding the decision making and easy to discuss with interrelated other designer about modularization. For these reasons, this paper suggest three material connection types; physical, chemical, and combination connection. Physical connection is defined as combination of touching and connected concepts in BSI ball diagram definitions, expression by line. Chemical connection is defined as used in connection by glue, welding, and permanent connection tools, expression by dotted line. Combination connection is used in same place both connection types physical and chemical, expression by both line and dotted line. Each symbol includes physical life cycle. Also, designer enters the material's physical life cycle into each ball. 
Step4. Combination of BSI Structure Based on Pre-Design Concepts

This step performed combination of BSI structure based on pre-design concepts as show in Figure 5. The main purpose of this step is defined connection types between each BSI models. Most of BSI models were not clearly defined as connection types between models because step 3 was focused on material's connection details. For this reason, designer defines each BSI model connection types in this step; physical, chemical, and combination connection.

\section{Step5. Finding an Alternative}

This step performed finding an alternative connection types or materials as shown in Figure 6. After the performed step 4, various limitations are extracted into possibility of adaption in modular units or not through the physical life cycle and connection type. Based on this information, designer organizing the main problems and performed the restart from step 1.This working will be end when there are no problems in this step. Summarizing the process from step 1 to step 4, proposed framework for modular units design process at the pre-design stage shown in Figure 7.

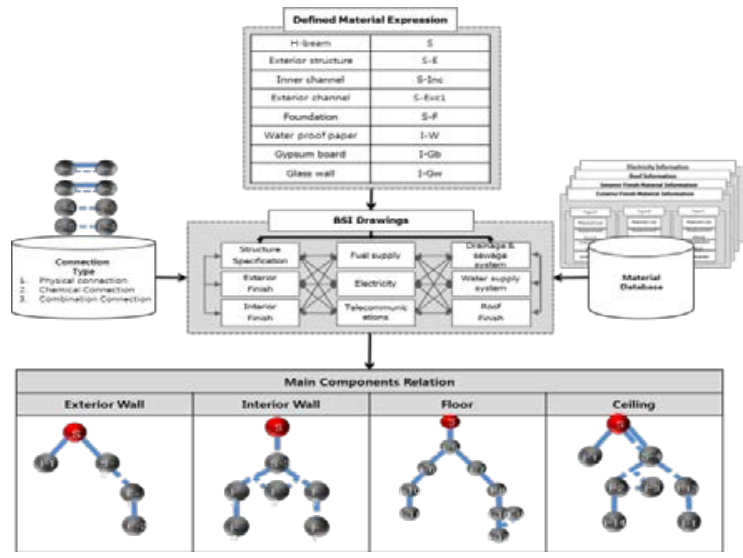

Figure 4. Step3, drawings BSI model structure

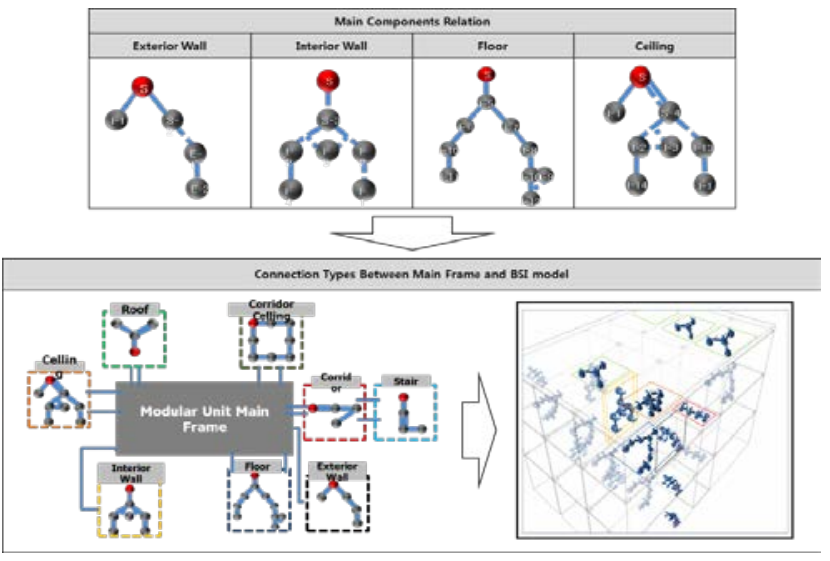

Figure 5. Step4, combination of BSI structure based on pre-design concepts

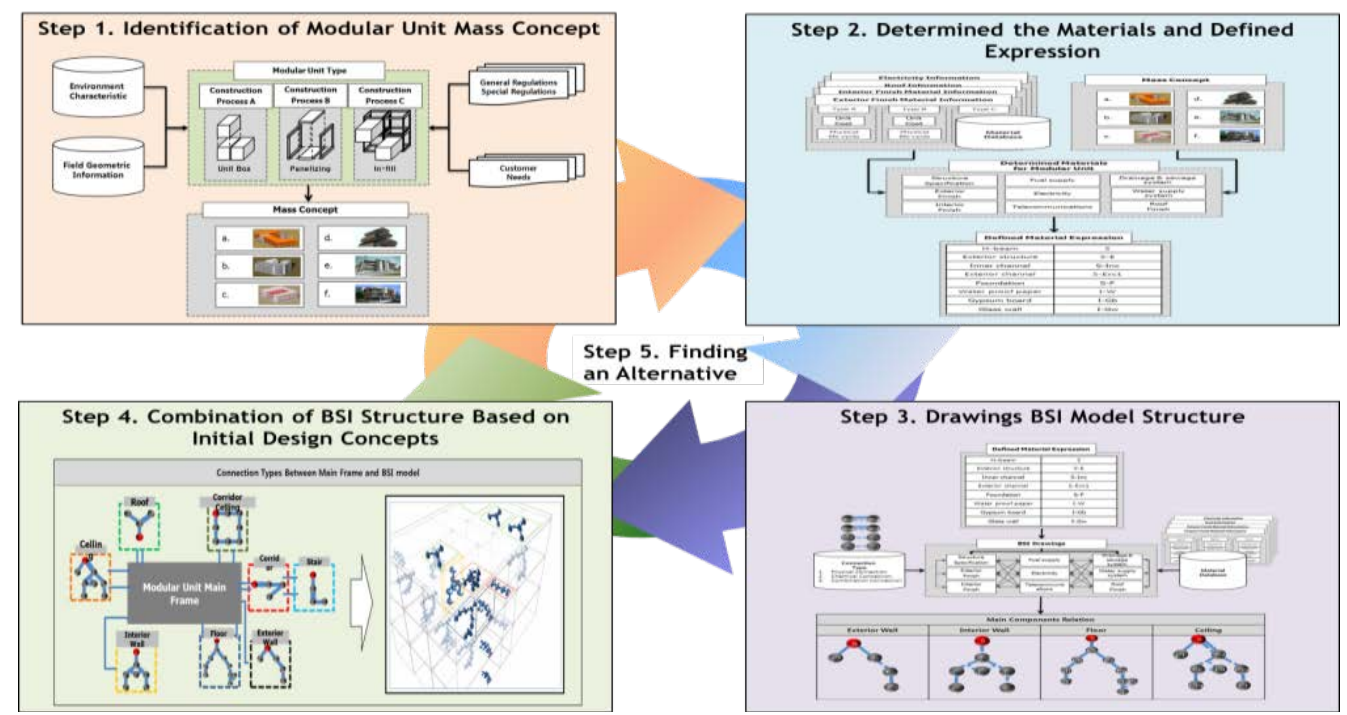

Figure 6. Step 5, Proposed Modular unit Design Process Framework Example 


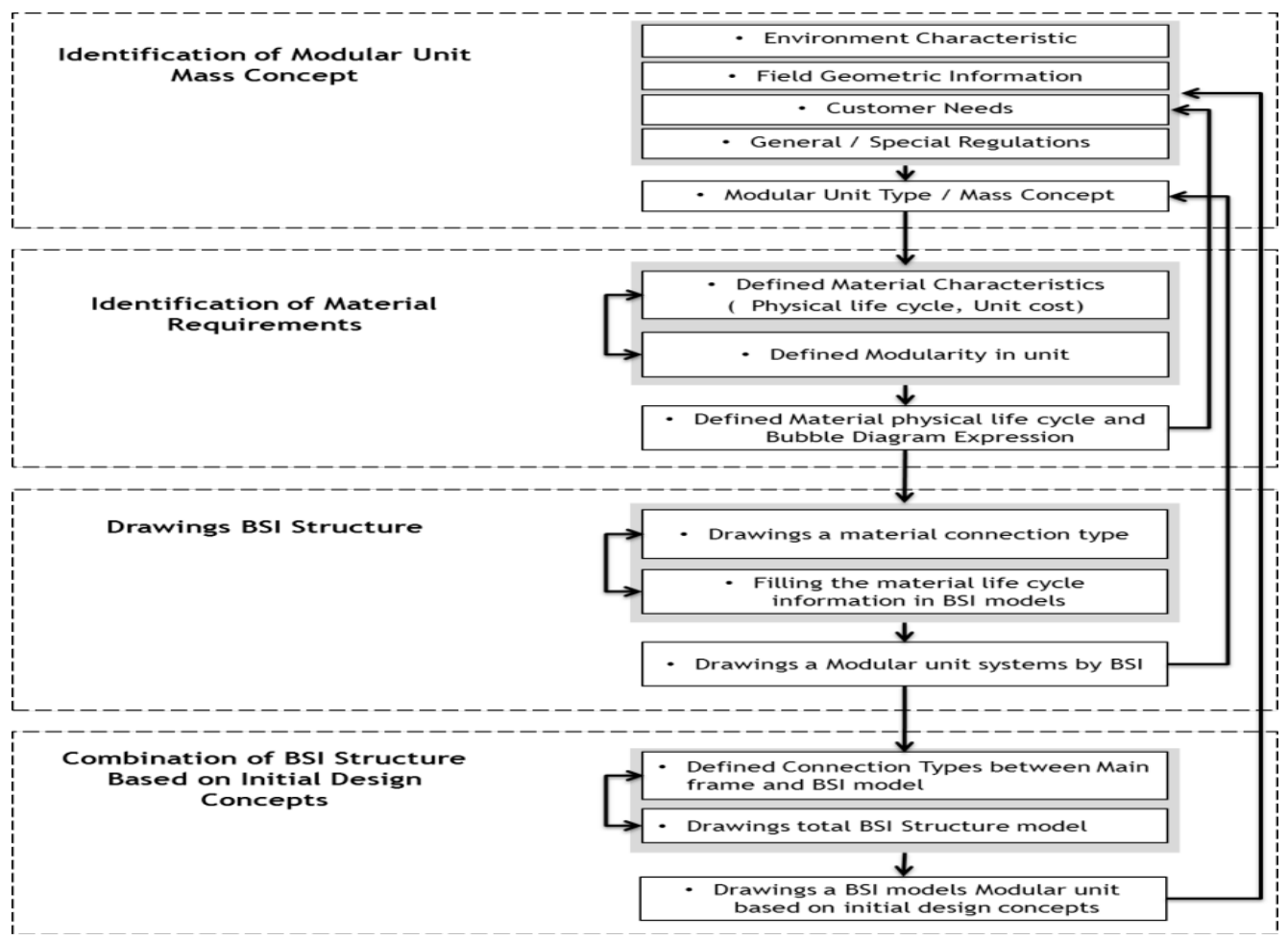

Figure 7. A framework for modular units design process at the pre-design stage

\section{CONCLUSION}

\section{Findings}

The purpose of this paper is to provide basic information of modular unit design process for inexperienced designer at the pre-design stage and improve the designers' understanding of modular design concepts by themselves using BSI methods. To achieve this purpose, proposed a modular design process framework and explain the main information following conventional building design process. As mentioned above, the intent of the developed framework proposed in this paper is to provide the conceptual modular building design process for inexperienced designer who not familiar with modular building design.

\section{Lessons learned}

Proposed framework contributions, as easy to understand the modular building design process and improve the inexperienced designer's modular design concepts understanding, could not apply all of inexperienced designers because it depends on designers' willingness of efforts to improve their understanding of modular building design concepts and skills of design intent expression. Rush[1986] mentioned about ways of improving architect skills, proposed framework is useful to improve the inexperienced designer's modular building design process and understanding of modular concepts ; “Architects don't learn to design by reading books. Every architect's learning process is by direct experience and takes a lifetime. Each building design is a lesson, and it usually offers substantial proof that the architect skill has unanswered questions about the subject. Improving design skills requires the architect's recognition of the flaws in his or her own work. It is a results of comparison with the work of others and analysis of ways each individual achieves integration of systems.” 


\section{ACKNOWLEDGEMENTS}

This research was supported by a grant (14RERP-B082884-01) from Housing Environment Research Program funded by Ministry of Land, Infrastructure and Transport of Korean government.

\section{REFERENCES}

A.Alwisy, M.Al-Hussein and S.H. AL-Jibouri (2012). "BIM Approach for Automated Drafting and Design for Modular Construction Manufacturing” Computing in Civil Engineering 2012, 221-228

CHEN et al, (2010). “A Research into Innovative Modular Design in the Logistics system”, Logistics for sustained Economic Development, ICLEM 2010, ASCE, 549-556

DAVORIN KRALJ, MIROKO MARKIC (2008). "Building Materials Reuse and Recycle”, 2008 WSEAS Transactions on Environment and Development

Elma Durmisevic (2006). "Transformable Building Structure”, University of Delft, Doctor Philosophy.

F. van Gassel, M.Roders (2006). "A Modular Construction System. How to design its production process”, 2006 International Conference on Adaptable Building Structures.

Mahdi Nasereddin, Michael A.Mullens, Dayana Cope. (2007) "Automated simulator development: A strategy for modeling modular housing production”. Automation in Construction 16, 212-223

Mullens, Michael (2004). "Production flow and shop floor control: Structuring the modular factory for custom homebuilding”, In Proceedings of the NSF Housing Resesarch Agenda Workshop, Vol.2.Fe. 12-14

Nawari O. Nawari (2012). "BIM Standard in Off-Site Construction”, Journal of Architectural Engineering, June 2012, ASCE. 107-113

P.Gu, S.Sosale (1999). "Product modularization for life cycle engineering", Robotics and Computer Integrated Manufacturing, Vol.15, Issue 5. 387-401

Rush RD(1986). “The Building systems integration handbook.” Stoneham, MA:ButterworthHeinimann.

Reid R.Senescu, John R.Haymaker, Sebastjan Meza, and Martin A. Ficsher (2012). "Design Process Communication Methodology: Improving the effectiveness and efficiency of collaboration, sharing, and understanding”, Journal of Architectural Engineering, ASCE.

Wenfa hu (2005). "Automatic Construction Process of Prefabricated Buildings on Geometric Reasoning”, Construction Research Contress 2005.

Yorkon Co. (2010) “A Guide to Improving the Whole Life Value of a Building” . Yorkon.Co. 